Review

\title{
Role of DKK4 in Tumorigenesis and Tumor Progression
}

\author{
Xinjia Cai, Zhigang Yao, Long Li and Junhui Huang \\ Department of Oral Pathology, Xiangya Stomalogical Hospital, Central South University, 410078, Chansha, Hunan, China \\ $\triangle$ Corresponding author: 808003@csu.edu.cn (Junhui Huang); Tel.: +86-138-7313-0110 \\ (c) Ivyspring International Publisher. This is an open access article distributed under the terms of the Creative Commons Attribution (CC BY-NC) license \\ (https://creativecommons.org/licenses/by-nc/4.0/). See http://ivyspring.com/terms for full terms and conditions.
}

Received: 2017.12.13; Accepted: 2018.03.26; Published: 2018.04.26

\begin{abstract}
Tumor is the most public health problem. The Wnt signal pathway extensively participates in diverse progresses containing embryonic development, maintenance of homeostasis and tumor pathogenesis. The Wnt signal pathway consists of canonical signal pathway, noncanonical Wnt/PCP pathway and noncanonical Wnt/Ca2+ pathway. The deletion of the ligand of Wnts results in cytoplasmic $\beta$-catenin phosphorylation, stopping entry of $\beta$-catenin to nuclear in canonical Wnt signaling. Instead, binding of Wnts to frizzled (FZ/FZD) as well as LRP5/6 causes activation of Wnt signal pathways. This facilitates entry of $\beta$-catenin to nuclear. The Dickkopf proteins (DKKs) have been known as the antagonist of Wnt signal pathway. A number of research of DKK1, 2, 3 have been reported, however, the effect of DKK4 on tumor process is still mysterious. A more distinct comprehension about the effect of DKK4 on tumorigenesis and tumor process will shed light on biomedical research of DKK4 and tumor research. This review summarizes the current knowledge of DKK4 in various kinds of tumors.
\end{abstract}

Key words: Tumor; Wnt signal pathway; $\beta$-catenin; DKK4

\section{Introduction}

The Dickkopf proteins include four secretory protein (DKK1, 2, 3, 4), cantaining 2 conserved sequences rich in cysteine correspond to region C24-C73 and region C128-C201 of DKK4. In regions rich in cysteine, there are some $\beta$-strand stretches in limited number of secondary structure [1]. A number of research of DKK1, 2, 3 and tumor pathogenesis have been reported, however, the effect of DKK4 on tumor process is still mysterious. In this review, we summarize the roles of DKK4 that contribute to the pathology observed in various kinds of tumors.

\section{Wnt Signal Pathway}

The Wnt signal pathway extensively participates in diverse progresses containing embryonic development, maintenance of homeostasis and tumor pathogenesis [2]. The Wingless (Wnt) gene was first screened in Drosophila melanogaster [3]. The Wnt signal pathway consists of canonical signal pathway, noncanonical Wnt/PCP pathway and noncanonical Wnt/Ca2+ pathway. Axin, APC and GSK3 $\beta$ combine to form destructive compound in the canonical pathway. Binding of cytoplasmic $\beta$-catenin to destructive compound brings its proteasomal deterioration, preventing nuclear accumulation [4]. Instead, the canonical Wnt ligand bind to FZ and LRP5/ 6 that leads to bonding with cell membrane of disheveled (Dsh/Dvl) and activation of Wnt signal pathways [5]. The combination of FZ and activating Dsh absorbs GSK3 $\beta$ and Axin to cell membrane, inactivating destructive compound. This increases stability and entry of $\beta$-catenin to nuclear.

Binding of Wnt ligand to non-canonical FZ activated the Wnt/PCP signal pathway [6]. This signal is transduced through interacting of Dsh/Dvl and FZ. The other branch of Wnt/PCP signal modifies actin cytoskeleton by stimulating activity of JNK. Binding of ligand to FZ activates the phospholipase C (PLC) in Wnt/Ca2+ pathway. This activation as well as the increase of intracellular second messengers $\mathrm{Ca} 2+$ changes the cellular functions. Increased levels of $\mathrm{Ca} 2+$ activated calcium-sensitive enzymes to mediate gene transcription. Overall, Wnt/PCP pathway take part in cell morphogenetic processes, and 
the Wnt/Ca2+ pathway control cell apoptosis and migration $[7,8]$. It's critical for development that both of the Wnt/PCP pathway and Wnt/Ca2+ pathway can mediate actin polymerization in morphogenesis [9].

The DKKs have been known as the antagonist of Wnt signal pathway. The DKKs include DKK1, 2, 3, 4, comprising 255 to 350 amino acids as well as two CRDs. Of various Wnt signal pathways, DKKs specifically inhibit canonical Wnt signal. In Wnt signal pathway, LRP5/ 6 can interact with DKK1, DKK2 and DKK4 except for DKK3. The dominant role of Dkk1 is to prevent the interaction of Wnts and LRP5/6 and disrupt the formation of FZ and LRP5/6 complex. DKK1 and DKK2 can also bind to the other receptors, Kremen1/2 (Krm1/2), which improves the inhibition of Wnt signal pathway by DKK1. Other than DKK1, DKK2 can be either active or inhibitive, depending on the internal environment [10].

\section{Role of DKK4 in Tumorigenesis and Tumor Progression}

There are a lot of researches concerning DKK4 in various cancer. But DKK4 plays different roles in all kinds of cancer. The effect of DKK4 on tumor process is still mysterious. It's necessary to categorize the findings of DKK4 in different cancer types to distinguish different roles of DKK4 in various cancer and help for detailed studies of physiological action of DKK4 in cancer in the future.

\section{DKK4 in Hepatocellular Carcinoma (HCC)}

Liao et al. showed that DKK4 reduced in $67.5 \%$ of cancer samples [11]. And Fatima et al. observed that DKK4 mRNA down-regulated in $47 \%$ of HCC tissues by RT-PCR. DKK4 protein reduced in 58\% cancerous tissues relative to corresponding noncancerous liver tissues by immunohistochemical analysis [12]. A recent study of HCC tissues and normal tissues reported that DKK4 mRNA expression decreased in $56.8 \%$ of 44 tumor tissues compared to normal tissue sample, with 1 undetectable sample. Tissue chips of 224 liver cancer and adjacent samples identified that DKK4 was positively expressed in $29.1 \%$ of cancerous tissues and $48.5 \%$ of adjacent tissues. DKK4 was positively expressed in $60 \%$ of 10 normal liver samples. In general, DKK4 expressions in transcription and translation level were lower in HCC than in adjacent normal samples [13](Table 1).

It was reported that overexpression of DKK4 decreased cell multiplication, migration and invasion. Conversely, Knockdown of DKK4 by shRNA promoted proliferation and restored cell invasiveness [14]. Tumor sizes reduction was observed in DKK4 induced nude mice. Tumors from DKK4 transfected decreased $\beta$-catenin level in cytoplasm, and down-regulated level of c-Jun, cyclin D1 and CD44 $[11,12]$. The change of $\beta$-catenin in nucleus was not reported. It suggested that DKK4 can't suppress the canonical Wnt signal pathway solely and need additional components. The levels of total GSK3 $\beta$ was unaltered in HCC stable cell line overexpressing DKK4, but the levels of phospho-GSK3 $\beta$ decreased. Inhibition of GSK3 $\beta$ by $\mathrm{LiCl}$ or 6 -Bromoindirubin3'-oxime (BIO) can hamper DKK4 induced suppression of proliferation by stabilizing $\beta$-catenin [14]. Overall, active GSK3 $\beta$ may be important for DKK4mediated inhibition and $\beta$-catenin phosphorylation [12].

Cui et al. identified that a majority of DKK4 protein expressed in cell cytoplasm. $\beta$-catenin currently gathered in tenuigenin and nucleus in HCC samples. But in adjacent liver tissues, it was observed in cell membrane and cytoplasm. Compare to corresponding adjacent tissues, $\beta$-catenin protein was overexpressed in HCC cancerous samples. The DKK4 was inverse associated with the level of $\beta$-catenin in cell nucleus. This further suggested that DKK4 might be able to modulating $\beta$-catenin nuclear entry. The total post-treatment survival in group of overexpressed DKK4 was more than decreased group. This demonstrated that DKK4 could be able to suppress tumor progression and inhibit the proliferation of HCC. Expression of DKK4 in HCC could be one factor of prognosis [13].

Studies of DKK4 expression identified that binding of TR to nucleotides 1645-1629 of promoter of DKK4 gene is related to T3-dependent DKK4 transcription. Triiodothyronine (T3) and TR upregulate the level of DKK4 to inhibit the Wnt signaling and tumor progression [11, 15]. One of the most critical features of tumor cells is able to rapidly absorbing and efficiently utilizing glucose, accelerating proliferation. It has been shown that the interaction of expression and function between c-Myc, DKK4 and $\beta$-catenin can facilitate HCC proliferation in high glucose conditions. Hyperglycemia diminishhes DKK4 protein and activates canonical Wnt signal pathway by transporting $\beta$-catenin to nucleus, thus accelerating HCC cell proliferation. DKK4 inactivates canonical Wnt signal pathway and interrupts multiplication specifically in phase G0/G1-S of cell cycle. These results demonstrated that DKK4 inhibits high glucose guided cell multiplication of HCC rely on $\beta$-catenin [14].

\section{DKK4 in Colorectal Cancer (CRC)}

Upregulation of DKK4 is observed in CRC. DKK4 was hypermethylated in $20 \%$ of colorectal cancer tissues [16]. Sato et al. found that DKK4 gene 
was silenced in $56 \%$ of CRC cells. But silence of DKK4 gene wasn't observed in normal colon tissues [17]. Xi et al. showed that colorectal cancer tissues have a higher expression of DKK4 compared to normal samples. And no expression with DKK4 was detectable in ten normal tissues [18]. Pendas-Franco observed expression of DKK4 increased in tumor samples but not detected in normal colon biopsies [19]. Baehs et al. demonstrated that the level of DKK4 expression is lower in $57.1 \%$ of tumors than matched normal epithelium [20]. Matsui et al. identified that DKK4 was strongly expressed in colorectal cancers compared with normal adjacent mucosae [21]. Overall, DKK4 was overexpressed in colorectal cancer compared to normal tissue by RT-PCR and IHC, indicating the upregulation of DKK4 in CRC.

Expression of DKK4 was positively related to $\beta$-catenin in CRC. As a typical $\beta$-catenin transcriptive objective gene, fibroblast growth factor- 20 was also positively correlated with the level of DKK4 in colorectal tumors [21]. Knockdown of DKK4 upregulates expression and decreases phosphorylation of $\beta$-catenin. DKK4 could be activated by the induction of the canonical pathway as a part of negative feedback loops [16]. DKK4 is an inhibitor of T-cell factor (TCF)-dependent signal in CRC cells. Deficience of DKK4 enhanced the growth of cancer cells. The DKK4 growth inhibition was attributed to arresting the G0/G1 phase. These suggest that DKK4 might be a critical regulatory gene of CRC cell growth [20]. DKK4 enhanced the metastasis, aggression and angiogenic potential of CRC. The effects of DKK4 on CRC cells and its overexpression in colorectal cancer suggest tumor promoting actions. Remarkable positive correlation in colorectal cancers among DKK4 expression and $\beta$-catenin nucleus entry suggested that DKK4 might be a downstream gene of canonical Wnt signaling. Suppression of canonical Wnt signal pathway may be partial effect induced by DKK4. DKK4 overexpression could be the side effect of the activation of Wnt/canonical signal. DKK4 also play a role beyond suppression of Wnt/canonical signal [19, 21]. It has been demonstrated that $1 a, 25$-dihydroxyvitamin D3 can inhibit DKK4 expression. There may be 2 mechanisms: (a) bonding of vitamin $\mathrm{D}$ receptor with DKK4 promoter; (b) mediately by the TCF/ $\beta$-catenin-connection sites. 1a, 25-dihydroxyvitamin D3 might be able to inhibit DKK4 expression [19] (Figure 1).

No expression of DKK4 in colorectal normal tissues suggests that DKK4 may be a potential gene for anticancer drug [18]. A recent study reported that DKK4 might take part in migration and apoptosis in cancer cells with treatment of 5-fluorouracil and YN968D1. DKK4 could increase the resistance of CRC cells to the treatment of 5-Fu and YN968D1 [22]. As a potential downstream target of TFAP2E, DKK4 mediated TFAP2E-dependent resistance has been identified, targeted therapy of DKK4 might get over TFAP2E-induced tolerance [23].

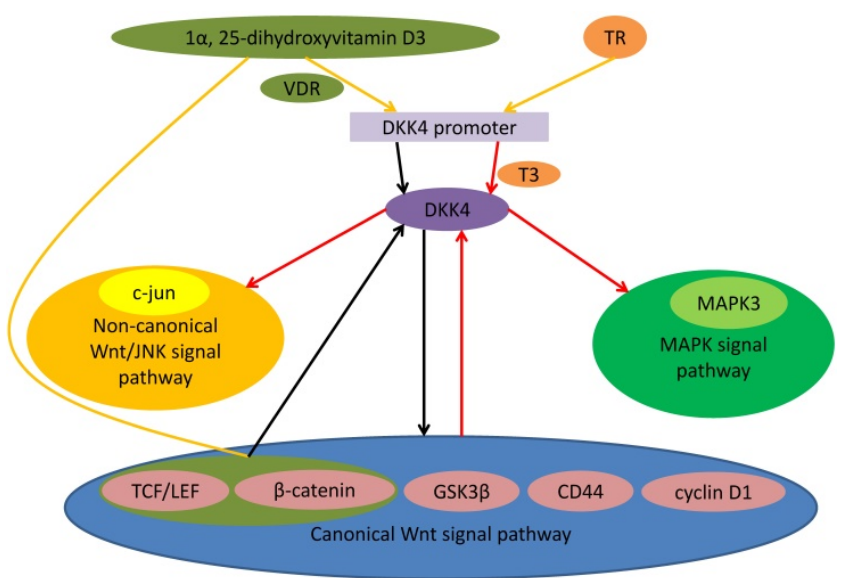

Figure 1. Role of DKK4 in different signal pathway. Binding of TR to nucleotides 1645-1629 of promoter of DKK4 gene is related to T3-dependent DKK4 transcription. Triiodothyronine (T3) and TR up-regulate the mRNA and protein levels of DKK4 expression. 1a, 25-dihydroxyvitamin D3 might be able to inhibit DKK4 expression. There may be 2 mechanisms: (a) bonding of vitamin D receptor with DKK4 promoter; (b) mediately by the TCF/ $\beta$-catenin-connection sites. DKK4 inhibites activity of TCF/LEF and down-regulates nuclear $\beta$-catenin entry. As the downstream effector, c-Myc as well as cyclin D1 also expressed at a low level. Meanwhile DKK4 decreases levels of phosphorylated GSK3 $\beta$ and up-regulates levels of phosphorylated $\beta$-catenin to antagonize the canonical Wnt signaling. Activating canonical Wnt signaling can induce expression of DKK4 as a negative feedback loop. DKK4 up-regulates and phosphorylates c-Jun and activates the non-canonical JNK signaling. DKK4 can activate the MAPK signal pathway through coexpression with MAPK3.

\section{DKK4 in Gastric Cancer (GC)}

It was demonstrated that $45.8 \%$ of gastric cancer tissues showed DKK4 mRNA overexpression, 55.9\% positive expression of DKK4 protein and $37.5 \%$ hypermethylation of gene DKK4. The methylation of DKK4 was correlated with its downregulation in gastrointestinal cancer cells and tissues. There were several CpG islands in promoter sequence of DKK4, but the methylation of $\mathrm{CpG}$ in cancer was more than in normal samples [16]. Aung et al. demonstrated that DKK4 protein was detected in $1.3 \%$ of gastric cancer, while the DKK4 mRNA was identified in $25 \%$ of GC. Most of DKK4 was observed in duodenum mucosa by qRT-PCR. Immunostaining for DKK4 was inspected in a minority of epithelia in the duodenum. The qRT-PCR result of mass GC samples might be not confined to reflecting DKK4 expression in cellular level. DKK4 overexpressed cells were also observed in the metaplasia of intestinal epithelium in stomach. Up-regulation of DKK4 mRNA detected in qRT-PCR could be caused by non-tumor sample stain, for instace, metaplasia of intestinal epithelium [24]. 
Table 1. DKK4 expression in different types of tumors

\begin{tabular}{|c|c|c|c|c|c|c|c|}
\hline Cancer & $\begin{array}{l}\text { First Author, } \\
\text { Published Year }\end{array}$ & Methods & $\begin{array}{l}\text { Samples (cancer and } \\
\text { matched tissues) }\end{array}$ & $\begin{array}{l}\text { Age } \\
\text { (mean) }\end{array}$ & Gender & Results & P Value \\
\hline \multirow[t]{6}{*}{ HCC } & \multirow{2}{*}{$\begin{array}{l}\text { Liao et al. } \\
2012\end{array}$} & IHC & 117 & \multirow[t]{4}{*}{55.7} & M: $90 \mathrm{~F}: 27$ & DKK4 protein down-regulated in $67.5 \%$ of HCC; & \\
\hline & & TM & 40 & & & $\begin{array}{l}\text { Stained strongly in } 10 \% \text { of } \mathrm{HCC} \\
\text { while } 67.5 \% \text { of normal cells }\end{array}$ & \\
\hline & \multirow{2}{*}{$\begin{array}{l}\text { Fatima et al. } \\
2012\end{array}$} & Real-time qPCR & 81 & & & DKK 4 mRNA down-regulated in $47 \%$ of HCC; & $\mathrm{P}<0.05$ \\
\hline & & $\mathrm{IHC}$ & 41 & & & DKK4 protein down-regulated in $58 \%$ of $\mathrm{HCC}$ & \\
\hline & \multirow[t]{2}{*}{$\begin{array}{l}\text { Cui et al. } \\
2017\end{array}$} & Real-time qPCR & 45 & 52.8 & M: 36 F: 9 & $\begin{array}{l}\text { DKK } 4 \text { mRNA down-regulated in } 56.8 \% \text { of HCC (1 } \\
\text { undetected); }\end{array}$ & $\mathrm{P}<0.05$ \\
\hline & & $\mathrm{TM}$ & 224 & 50.3 & M: 192 F: 32 & $\begin{array}{l}\text { DKK } 4 \text { protein positive in } 29.1 \% \text { of HCC while } \\
48.5 \% \text { in adjacent tissue }\end{array}$ & $\mathrm{P}<0.05$ \\
\hline \multirow[t]{6}{*}{ CRC } & $\begin{array}{l}\text { XI et al. } \\
2008\end{array}$ & Real-time qRT-PCR & 24 & 62 & M: 14 F: 10 & $\begin{array}{l}\text { DKK4 up-regulated in CRC than in } 14 \text { normal } \\
\text { samples ( } 10 \text { normal samples undetected) }\end{array}$ & $\mathrm{P}<0.05$ \\
\hline & \multirow{2}{*}{$\begin{array}{l}\text { Maehata et al. } \\
2008\end{array}$} & Semi qRT-PCR & \multirow[t]{2}{*}{30} & & & \multicolumn{2}{|l|}{ DKK4 mRNA up-regulated in $53.3 \%$ of CRC; } \\
\hline & & IHC & & & & \multicolumn{2}{|l|}{ DKK4 protein up-regulated in $58.3 \%$ of CRC } \\
\hline & $\begin{array}{l}\text { Pendas-Franco et al. } \\
2008\end{array}$ & qRT-PCR & 29 & & & $\begin{array}{l}\text { DKK4 mRNA up-regulated in CRC, not detected in } \\
\text { normal colon tissues }\end{array}$ & \\
\hline & $\begin{array}{l}\text { Baehs et al. } \\
2009\end{array}$ & qRT-PCR & 21 & & & DKK4 mRNA down-regulated in $57.1 \%$ of CRC & \\
\hline & $\begin{array}{l}\text { Matsui et al. } \\
2009\end{array}$ & Real-time RT-PCR & 21 & 69 & M: 13 F: 8 & DKK4 mRNA tumor/normal: 27.4 & $\mathrm{P}<0.01$ \\
\hline \multirow[t]{4}{*}{ GC } & \multirow{2}{*}{$\begin{array}{l}\text { Aung et al. } \\
2006\end{array}$} & qRT-PCR & 44 & & & \multicolumn{2}{|l|}{ DKK4 mRNA up-regulated in $25 \%$ of GC; } \\
\hline & & IHC & 151 & & & DKK4 protein positive in $1.3 \%$ of GC & \\
\hline & \multirow{2}{*}{$\begin{array}{l}\text { Maehata et al. } \\
2008\end{array}$} & Semi qRT-PCR & 24 & & & \multicolumn{2}{|l|}{ DKK4 mRNA up-regulated in $45.8 \%$ of GC; } \\
\hline & & IHC & & & & DKK4 protein up-regulated in $55.9 \%$ of GC & \\
\hline \multirow[t]{2}{*}{ PC } & \multirow{2}{*}{$\begin{array}{l}\text { Ouyang et al. } \\
2016\end{array}$} & qRT-PCR & 15 & & & \multicolumn{2}{|l|}{ DKK4 mRNA up-regulated } \\
\hline & & IHC & $\begin{array}{l}30 \text { cancer and } 7 \\
\text { normal samples }\end{array}$ & & & \multicolumn{2}{|l|}{$\begin{array}{l}\text { DKK4 protein positive in PC but negative in normal } \\
\text { tissues }\end{array}$} \\
\hline \multirow[t]{2}{*}{ RCC } & $\begin{array}{l}\text { Hirata et al. } \\
2011\end{array}$ & Real-time qRT-PCR & 30 & 60.3 & M: 17 F: 13 & \multicolumn{2}{|l|}{ DKK4 mRNA up-regulated in $63.3 \%$ of RCC } \\
\hline & $\begin{array}{l}\text { WEI et al. } \\
2014\end{array}$ & RT-PCR & 30 & 59 & M: 18 F: 12 & DKK4 mRNA up-regulated in $63.3 \%$ of RCC & \\
\hline \multirow[t]{3}{*}{ OC } & \multirow[t]{3}{*}{$\begin{array}{l}\text { Wang et al. } \\
2017\end{array}$} & qRT-PCR & 33 & & & $\begin{array}{l}\text { Relative DKK } 4 \text { mRNA expression: } 3.63 \pm 2.84 \text { in OC } \\
\text { while } 1.66 \pm 1.36 \text { in benign ovarian tumor; }\end{array}$ & $\mathrm{P}<0.01$ \\
\hline & & Western Blot & 33 & & & $\begin{array}{l}\text { Relative DKK } 4 \text { protein expression: } 0.86 \pm 0.01 \text { in } \mathrm{OC} \\
\text { while } 0.37 \pm 0.03 \text { in benign ovarian tumor; }\end{array}$ & $\mathrm{P}<0.01$ \\
\hline & & IHC & 239 & & & DKK4 protein positive in $92.1 \%$ of OC & \\
\hline MB & $\begin{array}{l}\text { Valdora et al. } \\
2013\end{array}$ & qPCR & $\begin{array}{l}333 \text { cancer and } 22 \\
\text { normal tissues }\end{array}$ & & & DKK4 mRNA up-regulated & $\mathrm{P}<0.01$ \\
\hline
\end{tabular}

Notes: HCC: hepatocellular carcinoma; CRC: colorectal cancer; GC: gastric cancer; PC: pancreatic cancer; RCC: renal cell carcinoma; OC: ovarian cancer; MB: medulloblastoma; IHC: immunohistochemistry; TM: tissue microarray; qRT-PCR: quantitative reverse transcriptase-PCR; M: male; F: female.

\section{DKK4 in Pancreatic Cancer (PC)}

Maehata et al. showed that DKK4 mRNA was over-expressed in $42.9 \%$ of pancreatic cancer tissues [16]. Park et al. found that DKK4 protein was up-regulated as 8.06-fold [25]. A recent study reported that DKK4 expression in PC samples was more than adjacent samples in 15 pair specimens. Immunohistochemistry was used to detect DKK4 in 30 PC specimens and 7 cases of normal tissue. DKK4 was observed in a majority of pancreatic cancer tissues whereas negative in normal pancreatic specimens. According to the results of qRT-PCR and IHC, DKK4 was increased in PC tissues. Ouyang et al. determined that DKK4 expressed as same as MAPK3 and VAV3 in PC tissues. The MAPK signaling seems to be a critical signaling pathway in DKK4-overexpressed PC. MAPK3 might be a significant kinase of this signal pathway. As an important gene in this coexpressed gene nets, VAV3 is responsible for the proliferation and invasion of cancer. It was identified that DKK4 activates the MAPK signal pathway to promote PC progression by means of VAV3 [26].

\section{DKK4 in Renal Cell Carcinoma (RCC)}

Hirata et al. identified that expression of DKK4 increased in RCC samples compared to adjacent kidney samples. DKK4 inhibited activity of TCF/LEF and down-regulated nuclear $\beta$-catenin entry in renal cancer. As downstream effector, c-Myc as well as cyclin D1 also expressed at a low level in transfected DKK4 cells. These suggested that DKK4 could take part in $\beta$-catenin-dependent signaling as an inhibitor. Contrary to canonical Wnt signal pathway protein expression, it was showed that DKK4 promote tumor growth and increase invasion and migration ability, indicating that DKK4 affected cancer signaling else. In addition, DKK4 up-regulated and phosphorylated c-Jun and increased expression of matrix metalloproteinase-2. These indicated that DKK4 induces Wnt noncanonical/JNK signal and inhibits canonical signaling $[27,28]$. The DKK4 expression was 
related to the Von Hippel-Lindau (VHL) gene. It was reported that DKK4 was overexpressed in $50 \%$ of the VHL(-) group in contrast to $18 \%$ of the VHL(+) group. DKK4 is a potential oncogene. The overexpression of DKK4 might be associated with the renal cancer. DKK4 might take effect as downstream gene induced by VHL [29]. Apoptosis induced by DKK4 has not been observed. But DKK4 may be able to promote RCC proliferation, migration and invasion by acting the non-canonical JNK signal pathway.

\section{DKK4 in Ovarian Cancer}

A recent study reported that transcription and translation levels of DKK4 were increased in ovarian cancer than in benign tumor samples. Also, IHC reported positively expression of DKK4 in EOC samples. The overexpression of DKK4 was positively related to the late of FIGO and poor disease free survival time, indicatting that DKK4 could take part in procession of ovarian cancer. It was suggested that DKK4 may promote tumor metastasis and forming actin filaments by activating JNK signaling. Overall, it has been demonstrated that DKK4 was up-regulated in EOC. Overexpression of DKK4 symbolized ominous prognosis and promoted cancer metastasis by activating JNK in ovarian cancer tumorigenesis and development [30].

\section{DKK4 in Other Cancers}

Maehata et al. demonstrated that DKK4 levels in transcription and translation were up-regulated in $40.0 \%$ and $47.5 \%$ of esophageal cancer tissues respectively [16]. Wong identified that DKK4 was increased in endometrial cancer contrary to normal samples [31]. Maliszewska et al. identified that DKK4 was overexpressed in medullary thyroid carcinoma [32]. Valdora et al. demonstrated DKK4 upregulation in Medulloblastoma, activating negative feedback loop [33].

In conclusion, both transcription and translation of DKK4 are detected in HCC, CRC, GC, PC, RCC, ovarian cancer, and esophageal cancer et al. However, DKK4 is only down-regulated in hepatocellular carcinoma, while overexpressed in other cancers. It has been identified that DKK4 inhibits canonical Wnt signal pathway and down-regulates expression of nuclear $\beta$-catenin, but it could promote tumor progression by activating other Wnt non-canonical signaling, such as non-canonical JNK pathway. Effects of DKK4 in tumorigenesis and progression are different in various kinds of tumors. More researches are needed to confirm the mechanism.

\section{Abbreviations}

DKK4: Dickkopf homolog 4; GSK3 $\beta$ : glycogen synthase kinase $3 \beta$; FZ/FZD: frizzled; LRP5/6: low-density lipoprotein receptor-related protein $5 / 6$; JNK: c-Jun N-terminal kinase; TCF/LEF: T-cell factor/lymphoid enhancer factor.

\section{Acknowledgments}

The work was supported by grants of China Hunan Provincial Science and Technology Program (2017GK2265).

\section{Author Contributions}

Xinjia Cai, Zhigang Yao, Long Li and Junhui Huang contributed to the manuscript text. Xinjia Cai and Junhui Huang designed the concept and Xinjia Cai drafted the table and figure.

\section{Competing Interests}

The authors have declared that no competing interest exists.

\section{References}

1. Barkell AM, Holdsworth G, Waters LC, Veverka V, Slocombe PM, Muskett $\mathrm{FW}$, et al. Resonance assignment and secondary structure determination of full length human Dickkopf 4 (hDkk4), a secreted, disulphide-rich Wnt inhibitor protein. Biomolecular NMR assignments. 2015; 9: 147-51. doi:10.1007/s12104-014-9562-2

2. Rosenbluh J, Wang X, Hahn WC. Genomic insights into WNT/beta-catenin signaling. Trends in pharmacological sciences. 2014; 35: 103-9. doi:10.1016/j.tips.2013.11.007

3. Klaus A, Birchmeier W. Wnt signalling and its impact on development and cancer. Nature reviews Cancer. 2008; 8: 387-98. doi:10.1038/nrc2389

4. Voronkov A, Krauss S. Wnt/beta-catenin signaling and small molecule inhibitors. Current pharmaceutical design. 2013; 19: 634-64.

5. Gao C, Chen YG. Dishevelled: The hub of Wnt signaling. Cellular signalling. 2010; 22: 717-27. doi:10.1016/j.cellsig.2009.11.021

6. Sugimura R, Li L. Noncanonical Wnt signaling in vertebrate development, stem cells, and diseases. Birth defects research Part C, Embryo today: reviews. 2010; 90: 243-56. doi:10.1002/bdrc. 20195

7. Byrum CA, Xu R, Bince JM, McClay DR, Wikramanayake AH. Blocking Dishevelled signaling in the noncanonical Wnt pathway in sea urchins disrupts endoderm formation and spiculogenesis, but not secondary mesoderm formation. Developmental dynamics: an official publication of the American Association of Anatomists. 2009; 238: 1649-65. doi:10.1002/dvdy.21978

8. Kikuchi A, Yamamoto $\mathrm{H}$, Sato $\mathrm{A}$, Matsumoto $\mathrm{S}$. New insights into the mechanism of Wnt signaling pathway activation. International review of cell and molecular biology. 2011; 291: 21-71. doi:10.1016/b978-0-12386035-4.00002-1

9. Song JL, Nigam P, Tektas SS, Selva E. microRNA regulation of Wnt signaling pathways in development and disease. Cellular signalling. 2015; 27: 1380-91. doi:10.1016/j.cellsig.2015.03.018

10. Cruciat $\mathrm{CM}$, Niehrs C. Secreted and transmembrane wht inhibitors and activators. Cold Spring Harbor perspectives in biology. 2013; 5(a): 015081. doi:10.1101/cshperspect.a015081

11. Liao $\mathrm{CH}$, Yeh CT, Huang YH, Wu SM, Chi HC, Tsai MM, et al. Dickkopf 4 positively regulated by the thyroid hormone receptor suppresses cell invasion in human hepatoma cells. Hepatology (Baltimore, Md). 2012; 55: 910-20. doi:10.1002/hep. 24740

12. Fatima $\mathrm{S}$, Lee NP, Tsang $\mathrm{FH}$, Kolligs FT, $\mathrm{Ng}$ IO, Poon RT, et al. Dickkopf 4 (DKK4) acts on Wnt/beta-catenin pathway by influencing beta-catenin in hepatocellular carcinoma. Oncogene. 2012; 31: 4233-44. doi:10.1038/onc. 2011.580

13. Cui D, Wang Z, Wang T, Tang XY, Zhai B. Low expression level of Dickkopf 4 in hepatocellular carcinoma and its clinical significance. International journal of clinical and experimental pathology. 2017; 10: 760-9

14. Chouhan S, Singh S, Athavale D, Ramteke P, Pandey V, Joseph J, et al. Glucose induced activation of canonical Wnt signaling pathway in hepatocellular carcinoma is regulated by DKK4. Scientific reports. 2016; 6: 27558. doi:10.1038/srep27558

15. Chi HC, Liao CH, Huang YH, Wu SM, Tsai CY, Liao CJ, et al. Thyroid hormone receptor inhibits hepatoma cell migration through transcriptional activation of Dickkopf 4. Biochemical and biophysical research communications. 2013; 439: 60-5. doi:10.1016/j.bbrc.2013.08.028 
16. Maehata T, Taniguchi H, Yamamoto H, Nosho K, Adachi Y, Miyamoto N, et al. Transcriptional silencing of Dickkopf gene family by $\mathrm{CpG}$ island hypermethylation in human gastrointestinal cancer. World journal of gastroenterology. 2008; 14: 2702. doi:10.3748/wjg.14.2702

17. Sato H, Suzuki H, Toyota M, Nojima M, Maruyama R, Sasaki S, et al. Frequent epigenetic inactivation of DICKKOPF family genes in human gastrointestinal tumors. Carcinogenesis. 2007; 28: 2459-66. doi:10.1093/carcin/bgm178

18. Xi Y, Formentini A, Nakajima G, Kornmann M, Ju J. Validation of biomarkers associated with 5-fluorouracil and thymidylate synthase in colorectal cancer. Oncology reports. 2008; 19: 257-62.

19. Pendas-Franco N, Garcia JM, Pena C, Valle N, Palmer HG, Heinaniemi M, et al. DICKKOPF-4 is induced by TCF/beta-catenin and upregulated in human colon cancer, promotes tumour cell invasion and angiogenesis and is repressed by 1alpha,25-dihydroxyvitamin D3. Oncogene. 2008; 27: 4467-77. doi:10.1038/onc. 2008.88

20. Baehs S, Herbst A, Thieme SE, Perschl C, Behrens A, Scheel S, et al. Dickkopf-4 is frequently down-regulated and inhibits growth of colorectal cancer cells. Cancer letters. 2009; 276: 152-9. doi:10.1016/j.canlet.2008.11.003

21. Matsui A, Yamaguchi T, Maekawa S, Miyazaki C, Takano S, Uetake T, et al. DICKKOPF-4 and -2 genes are upregulated in human colorectal cancer. Cancer science. 2009; 100: 1923-30. doi:10.1111/j.1349-7006.2009.01272.x

22. He S, Shen J, Hu N, Xu X, Li J. DKK4 enhances resistance to chemotherapeutics 5-Fu and YN968D1 in colorectal cancer cells. Oncology letters. 2017; 13: 587-92. doi:10.3892/ol.2016.5461

23. Ebert MP, Tanzer M, Balluff B, Burgermeister E, Kretzschmar AK, Hughes DJ, et al. TFAP2E-DKK4 and chemoresistance in colorectal cancer. The New England journal of medicine. 2012; 366: 44-53. doi:10.1056/NEJMoa1009473

24. Aung PP, Oue N, Mitani Y, Nakayama H, Yoshida K, Noguchi T, et al. Systematic search for gastric cancer-specific genes based on SAGE data: melanoma inhibitory activity and matrix metalloproteinase-10 are novel prognostic factors in patients with gastric cancer. Oncogene. 2006; 25: 2546-57. doi:10.1038/sj.onc.1209279

25. Park M, Lim JS, Lee HJ, Na K, Lee MJ, Kang CM, et al. Distinct Protein Expression Profiles of Solid-Pseudopapillary Neoplasms of the Pancreas. Journal of proteome research. 2015; 14: 3007-14. doi:10.1021/acs.jproteome.5b00423

26. Ouyang Y, Pan J, Tai Q, Ju J, Wang H. Transcriptomic changes associated with DKK4 overexpression in pancreatic cancer cells detected by RNA-Seq. Tumour biology : the journal of the International Society for Oncodevelopmental Biology and Medicine. 2016; 37: 10827-38. doi:10.1007/s13277-015-4379-x

27. Hirata H, Ueno K, Nakajima K, Tabatabai L, Hinoda Y, Ishii N, et al. Dkk4 Activates Non-Canonical Jnk Signaling Pathway While Inhibiting the Wnt-Canonical Pathway In Human Renal Cell Carcinoma. Cancer. 2011; 117(8): 1649-1660

28. Hirata H, Hinoda Y, Majid S, Chen Y, Zaman MS, Ueno K, et al. DICKKOPF-4 activates the noncanonical c-Jun-NH2 kinase signaling pathway while inhibiting the Wnt-canonical pathway in human renal cell carcinoma. Cancer. 2011; 117: 1649-60. doi:10.1002/cncr.25666

29. Zhai W, Hu GH, Zheng JH, Peng B, Liu M, Huang JH, et al. High expression of the secreted protein dickkopf homolog 4: roles in invasion and metastasis of renal cell carcinoma and its association with Von Hippel-Lindau gene. International journal of molecular medicine. 2014; 33: 1319-26. doi:10.3892/ijmm.2014.1673

30. Wang S, Wei H, Zhang S. Dickkopf-4 is frequently overexpressed in epithelial ovarian carcinoma and promotes tumor invasion. BMC cancer. 2017; 17: 455. doi:10.1186/s12885-017-3407-1

31. Wong YF, Cheung TH, Lo KW, Yim SF, Siu NS, Chan SC, et al. Identification of molecular markers and signaling pathway in endometrial cancer in Hong Kong Chinese women by genome-wide gene expression profiling. Oncogene. 2007; 26: 1971-82. doi:10.1038/sj.onc.1209986

32. Maliszewska A, Leandro-Garcia LJ, Castelblanco E, Macia A, de Cubas A, Gomez-Lopez G, et al. Differential gene expression of medullary thyroid carcinoma reveals specific markers associated with genetic conditions. The American journal of pathology. 2013; 182: 350-62. doi:10.1016/j.ajpath.2012.10.025

33. Valdora F, Banelli B, Stigliani S, Pfister SM, Moretti S, Kool M, et al. Epigenetic Silencing of DKK3 in medulloblastoma. International journal of molecular sciences. 2013; 14: 7492-505. doi:10.3390/ijms14047492 